Research Article

\title{
Dielectric Studies on $\mathrm{Fe}_{3} \mathrm{O}_{4}$ Nanodoped $p$ - $n$-Alkyloxybenzoic Acids
}

\section{S. Sreehari Sastry, ${ }^{1}$ L. Tanuj Kumar, ${ }^{1}$ T. Vishwam, ${ }^{2}$ V. R. K. Murthy, ${ }^{3}$ S. Lakshminaryana, ${ }^{4}$ and $\mathrm{Ha}_{\mathrm{S}}$ Sie Tiong ${ }^{5}$}

${ }^{1}$ Department of Physics, Acharya Nagarjuna University, Nagarjuna Nagar 522510, India

${ }^{2}$ Department of Physics, Gitam University, Hyderabad Campus, Rudraram 502329, India

${ }^{3}$ Department of Physics, Indian Institute of Technology, Chennai 600036, India

${ }^{4}$ Department of Electronics and Communication Engineering, K.L. University, Greenfields, Vaddeswaram, Guntur, Andhra Pradesh 522002, India

${ }^{5}$ Departmant of Chemical Science, Faculty of Science, Universiti Tunku Abdul Rahman, Jalan Universiti, Bandar Barat, 31900 Kampar, Perak, Malaysia

Correspondence should be addressed to S. Sreehari Sastry; sreeharisastry@yahoo.com

Received 20 January 2014; Accepted 16 May 2014; Published 16 June 2014

Academic Editor: Victor V. Moshchalkov

Copyright (C) 2014 S. Sreehari Sastry et al. This is an open access article distributed under the Creative Commons Attribution License, which permits unrestricted use, distribution, and reproduction in any medium, provided the original work is properly cited.

The stability of phase transition temperatures and textural changes for thermotropic pure and nanodoped $p$ - $n$-alkyloxybenzoic acid mesogens were aimed to study at considerable time periods. Frequency and temperature dependent dielectric constant and dielectric loss for the pure and nanodoped liquid crystals were carried out. Significant anomalies in dielectric studies were observed near phase transitions when dielectric constant and dielectric loss had been measured as a function of temperature and frequency. Changes in dielectric constant and loss were observed and there were no apparent changes at high frequencies instead maintaining constant values. The variations in conductivity, activation energy, and relaxation times had also been studied in the nematic and smectic phases. The temperature dependent dielectric constant stability (temperature coefficient of dielectric constant $\tau_{\varepsilon}$ ) had shown shift in the observed frequency range of thermotropic liquid crystals corresponding to the change in the dielectric constant values.

\section{Introduction}

Nanodoped liquid crystal (LC) research has emerged an important potential area in scientific and technological applications especially in liquid crystal displays [1]. The liquid crystalline materials doped with nanoparticles have indeed attracted much scientific and technological interest mainly because the incorporation of nanomaterials enhances the physical properties of the liquid crystal itself [2]. Low doping concentrations $(<3 \%$ by weight $)$ are usually preferred to get a more stable and for an even distribution in the LC, which will lower the interaction forces between particles [3, 4]. $p$-n-alkyloxybenzoic acids are extensively studied earlier and gained interesting results [5-8]. Various experimental techniques are being done on these alkyloxybenzoic acids on individual members and on mixed compounds $[6,8-10]$.
Dielectric spectroscopy $[11,12]$ is an effective experimental tool to understand the doping of nanoparticles in liquid crystals. It all depends on intrinsic properties of charged material distribution in molecules and also the intermolecular interactions. The LC anisotropy is proven to have substantially increased due to introduction of nanoparticles (magnetic nanoparticles, basically ferric oxides) [13]. However, enhancement of the electrooptical properties of LC is dependent on the size, type, concentration, and intrinsic characteristics of nanoparticles that are used for doping [14, 15].

The present study aims to examine the stable conditions for the properties of textural, phase transitions, and dielectric properties from room temperature to more than its isotropic temperatures on nanodoped $p$ - $n$-alkyloxybenzoic acids. 


\section{Materials and Methods}

$p$ - $n$-Alkyloxybenzoic acids ( $n \mathrm{OBA}$ ) from $n=3$ to 10 and 12 are procured from Frinton Laboratories, Inc., USA. The ferric oxides $\left(\mathrm{Fe}_{3} \mathrm{O}_{4}\right)$ nanoparticles of $20 \mathrm{~nm}$ size are procured from Indian Institute of Technology, Chennai. Magnetite $\left(\mathrm{Fe}_{3} \mathrm{O}_{4}\right)$ nanoparticles of $0.1 \%$ are doped through continuous stirring for nearly 3 hours in their isotropic phase of $p$ - $n$ alkyloxybenzoic acids and after cooling the nanodoped $p-n$ alkyloxybenzoic acids ( $n n \mathrm{OBA}$ ) are subjected to study.

Textural and phase transition temperatures are measured using a Meopta polarising optical microscope (POM) with hot stage as described by Gray [16]. The pure and nanodispersed thermotropic LCs are filled in LC1 ITO coated cells, for $90^{\circ}$ twist aligned $(5 \mathrm{~mm} \times 5 \mathrm{~mm} \times 6 \mu \mathrm{m})$, which are obtained from $\mathrm{M} / \mathrm{s}$ Instec Inc., USA. The compounds in their isotropic state are filled in these cells through capillary action method. Textural and phase transition temperatures are studied after preparation of the sample and observations are made again after a gap of period to understand the stability of $\mathrm{Fe}_{3} \mathrm{O}_{4}$ nanoparticles.

The temperature and frequency dependence of capacitance $C$, resistance $R$, and inductance $L$ were measured by using Newton's 4th Ltd. LCR meter model PM1700. The cells filled with pure and nanodoped samples are placed in an Instec hot and cold stage (HCS 302) equipped with microscope (Olympus BX50) having DP10 camera setup. The temperature is monitored and controlled through a computer by a software program to an accuracy of $\pm 0.1^{\circ} \mathrm{C}$. The sample is heated to isotropic state and held until attaining thermal equilibrium. The data of $C, L$, and $R$ is taken during cooling process. The measuring signal is the square form with amplitude of $2 \mathrm{~V}$. The frequency range of measurement is from $100 \mathrm{~Hz}$ to $1 \mathrm{MHz}$. The accuracy of dielectric constant and loss are estimated to the error of $1 \%$ and $2 \%$, respectively.

\section{Results and Discussion}

3.1. Textures and Phase Transition Temperatures. The phases and their transition temperatures shown in Table 1 are obtained from POM for nanodoped $p$ - $n$-alkyloxybenzoic acids which exhibit enantiotropic behavior.

The phase transition temperatures for different series of those pure $p$ - $n$-alkyloxybenzoic acids [17] recorded immediately after preparation of $\mathrm{N} n \mathrm{OBA}$ are not similar as shown in Table 1. The clearing temperatures have decreased for nanodoped liquid crystals when compared to pure liquid crystals [18]. This decrease is due to increase in the van der Waals attraction among nanoparticles that disturbed the orientational properties of director in the LCs medium. Hence, the interaction among them excluding the neighbourhood molecules has formed strong anchoring conditions that influenced the specific orientation to the director resulting in topological defects $[19,20]$.

The nanoparticles appeared to be stabilized after many interactions among themselves within the liquid crystal medium. The mobility of these nanoparticles in liquid crystal medium is limited forming stable dispersions in alkyloxybenzoic acids. It means the surface anchoring properties became
TABLE 1: Phase transition temperatures of nanoalkyloxy benzoic acids.

\begin{tabular}{lccc}
\hline S. number & $\begin{array}{c}\text { Compound } \\
\text { NnOBA, } n=\end{array}$ & Textures & $\begin{array}{c}\text { Transition } \\
\text { temperatures }\left({ }^{\circ} \mathrm{C}\right)\end{array}$ \\
\hline 1 & 3 & $\mathrm{I}-\mathrm{N}-\mathrm{Cr}$ & $147.2-131.3$ \\
2 & 4 & $\mathrm{I}-\mathrm{N}-\mathrm{Cr}$ & $142.2-127.7$ \\
3 & 5 & $\mathrm{I}-\mathrm{N}-\mathrm{Cr}$ & $141.8-115.8$ \\
4 & 6 & $\mathrm{I}-\mathrm{N}-\mathrm{S}_{\mathrm{C}}-\mathrm{Cr}$ & $139.2-115.3-93.1$ \\
5 & 7 & $\mathrm{I}-\mathrm{N}-\mathrm{S}_{\mathrm{C}}-\mathrm{Cr}$ & $133.2-93.7-85.8$ \\
6 & 8 & $\mathrm{I}-\mathrm{Ch}-\mathrm{Cr}$ & $128.2-88.9$ \\
7 & 9 & $\mathrm{I}-\mathrm{N}-\mathrm{S}_{\mathrm{C}}-\mathrm{Cr}$ & $131.8-106.2-87.2$ \\
8 & 10 & $\mathrm{I}-\mathrm{S}_{\mathrm{A}}-\mathrm{S}_{\mathrm{B}}-\mathrm{Cr}$ & $95.8-82.8-67.2$ \\
9 & 12 & $\mathrm{I}-\mathrm{N}-\mathrm{S}_{\mathrm{C}}-\mathrm{Cr}$ & $118.8-107.5-87.8$ \\
\hline
\end{tabular}

Note: $\mathrm{I}=$ isotropic, $\mathrm{N}=$ nematic, $\mathrm{Ch}=$ cholesteric, $\mathrm{S}_{\mathrm{A}}=$ smectic $\mathrm{A}, \mathrm{S}_{\mathrm{B}}=$ smectic $\mathrm{B}$, and $\mathrm{S}_{\mathrm{C}}=$ smectic $\mathrm{C}$.

weak such that there is no director distortion in the liquid crystal phase. On the other hand, these features reveal clearly that the elastic energy dominates the magnetic one as long as the orientation of director is fixed [21]. The textures of nematic and smectic phases of pure and doped samples are shown in Figure 1. All the $n \mathrm{OBA}$ samples have exhibited both threaded nematic and smectic C [22] from $n=7$ to 10 and 12, whereas $n=3$ to 6 samples show only threaded nematic. In addition, the observed nanodoped $n \mathrm{OBA}$ liquid crystals have displayed threaded nematic and $\operatorname{Sm} \mathrm{C}$ for $n=6,7,9$, and 12 and cholesteric phase in nanodoped 8OBA and the phases of $\mathrm{Sm} \mathrm{A}$ and Sm B in nanodoped 10OBA.

These changes can be attributed to the increase in chain length, surface anisotropy, and even-odd effect which are commonly existing in homologous series [23]. The textural changes start playing into effect in nanodoped samples for $n=6$. This is a self-explanatory showing the effect of chain length increase on textures. The existence of cholesteric phase in N8OBA particularly is due to electroconvection that is usually existing in nematic liquid crystals of short range Sm C order [24]. Comparatively, among all in the selected homologous series of $n \mathrm{OBA}$, the $8 \mathrm{OBA}$ has displayed short range $\mathrm{Sm} \mathrm{C}$ (from $90.5^{\circ} \mathrm{C}$ to $98.5^{\circ} \mathrm{C}$ ). Hence, only in $8 \mathrm{OBA}$, the presence of nano has made it modified to cholesteric. With the order of chain length increase, the nanoparticles effect the alignment of LC molecules and try to bring them into layering which is identified as Sm A and Sm B. These textures corresponding to different phases are shown in Figures 1(e)-1(g).

The aggregation of magnetite nanoparticles appearing in the textures shown in Figure 2 is attributed to a large contribution to the magnetic anisotropy, which is likely to be located on the particle surface by overcoming randomly oriented molecules with uniaxial symmetry of mesophases.

The UV-visible spectroscopic studies have also confirmed the presence of magnetite nanoparticles in the lattice of samples.

The UV-visible spectra of pure and nanodoped 7OBA mesogen samples are shown in Figure 3. It is observed that the spectrum for pure 7OBA does not exhibit any absorption 


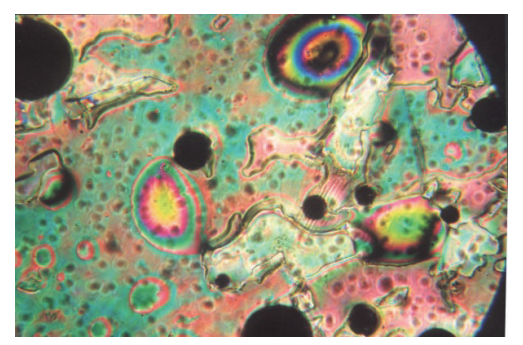

(a)

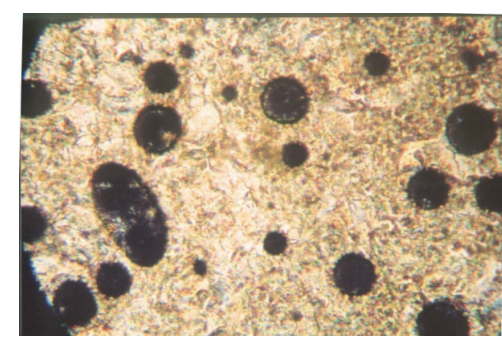

(b)

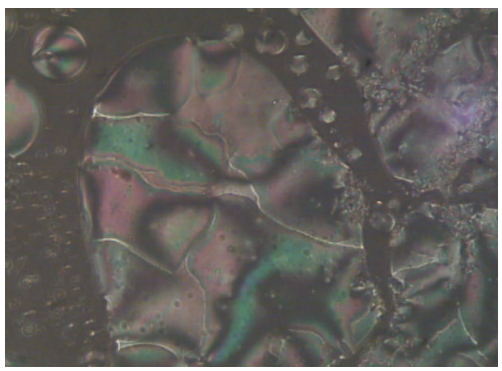

(c)

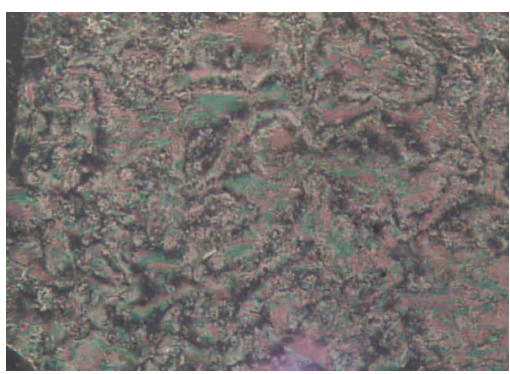

(d)

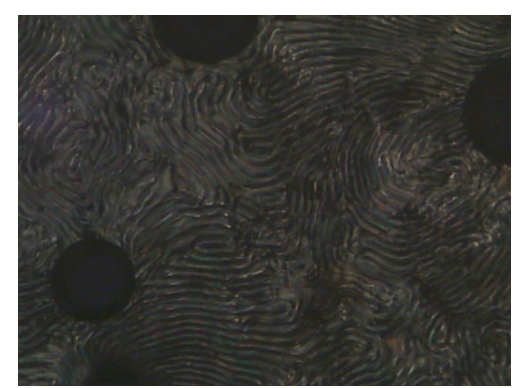

(e)

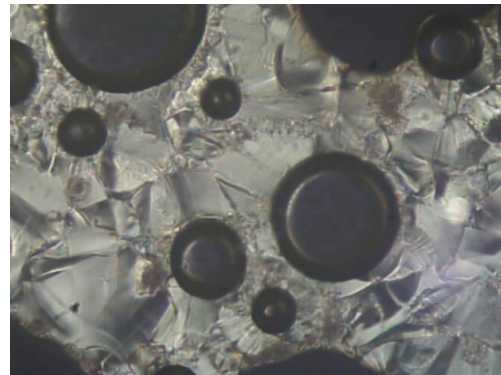

(f)

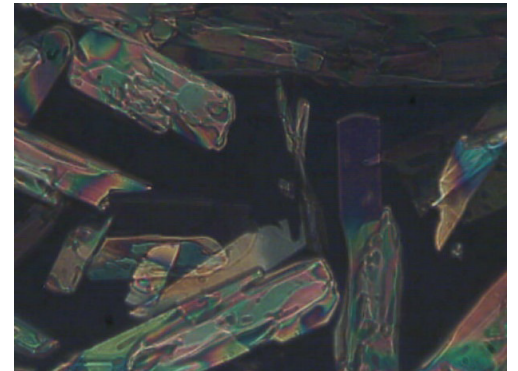

(g)

Figure 1: Textures of $n$ OBA. (a) Threaded nematic. (b) Smectic C and typical nanodoped $n$ OBA. (c) Nematic. (d) Smectic C. (e) Cholesteric in N8OBA. (f) Smectic A. (g) Smectic B in N10BA.

peaks in the wavelength range of $200 \mathrm{~nm}-2000 \mathrm{~nm}$. However, the spectrum of nanodoped 7OBA shows three significant peaks at $418 \mathrm{~nm}, 681 \mathrm{~nm}$, and $821 \mathrm{~nm}$, which are the characteristic peaks of $\mathrm{Fe}^{3+}$ ion [25]. So, the UV-visible spectral study confirms the presence of $\mathrm{Fe}_{3} \mathrm{O}_{4}$ nanoparticles in the prepared nanodoped mesogens.

\subsection{Dielectric Spectral Studies for Series of Pure and Nanodoped p-n-Alkyloxybenzoic Acids}

3.2.1. Frequency Dependence of Dielectric Constant and Temperature Coefficient of Dielectric Constant $\tau_{\varepsilon}$. The dielectric constant of a material is numerically the ratio of the capacitance of a capacitor containing that material to the capacitance of the same electrode system with vacuum.

Using (1), the dielectric constant $\left(\varepsilon^{1}\right)$ for series of pure and nanoalkyloxybenzoic acids is calculated:

$$
\varepsilon^{1}=\frac{\left(C_{p}-C_{o}\right) d}{\varepsilon_{o} A}+1
$$

where $A=$ area of the cell, $d=$ thickness of the cell, $\varepsilon_{0}=$ permittivity of free space $8.85 \times 10^{-12} \mathrm{Fm}^{-1}, C_{p}=$ capacitance with sample, and $C_{o}=$ capacitance without sample.

The temperature coefficient of dielectric constant $\left(\tau_{\varepsilon}\right)$ is calculated using (2). Values of $\tau_{\varepsilon}$ can be positive or negative, indicating an increasing or decreasing dielectric constant, respectively, with an increasing temperature [26]. As these are thermotropic liquid crystals, their temperature stability with respect to other materials is low [26]. To determine $\tau_{\varepsilon}$, the measured dielectric constant at isotropic temperature considered as reference temperature is compared with the values recorded at both initial and final phases given for temperature range of liquid crystal. Consider

$$
\begin{aligned}
\tau_{\varepsilon}= & \frac{\left(\varepsilon\left(T_{\text {final }}\right) / \varepsilon\left(T_{\text {ref }}\right)\right)-\left(\varepsilon\left(T_{\text {initial }}\right) / \varepsilon\left(T_{\text {ref }}\right)\right)}{T_{\text {final }}-T_{\text {initial }}} \\
& * 10^{6}\left[\mathrm{ppm} /{ }^{\circ} \mathrm{C}\right]
\end{aligned}
$$

where $T_{\text {initial }}=$ initial LC phase temperature value, $T_{\text {final }}=$ final LC phase temperature value, $\varepsilon\left(T_{\text {initial }}\right), \varepsilon\left(T_{\text {final }}\right)=$ the corresponding dielectric constant, and $\varepsilon\left(T_{\text {ref }}\right)=$ dielectric 


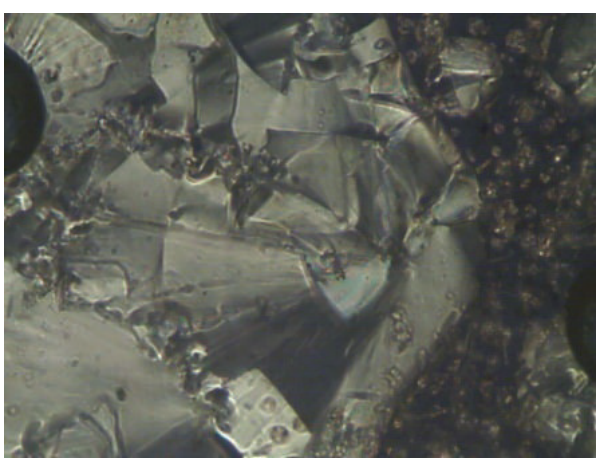

(a)

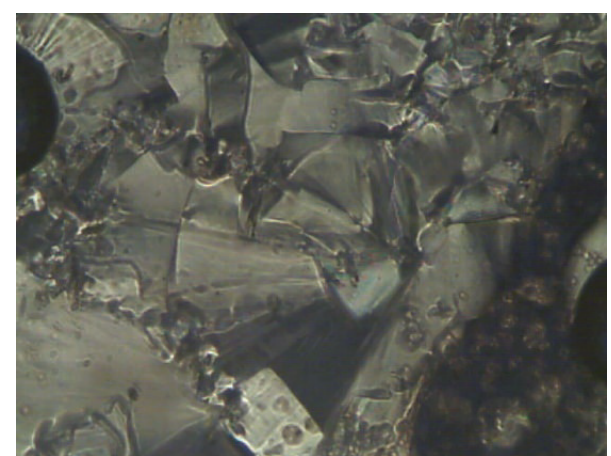

(b)

FIGURE 2: The aggregation of $\mathrm{Fe}_{3} \mathrm{O}_{4}$ nanoparticles in nanodoped 12OBA (brown color shade).

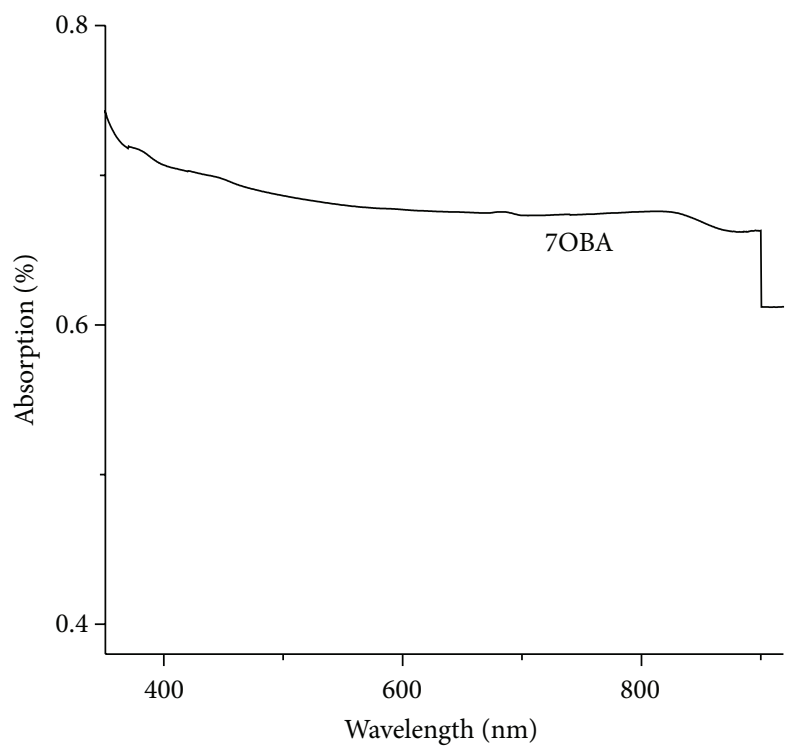

(a)

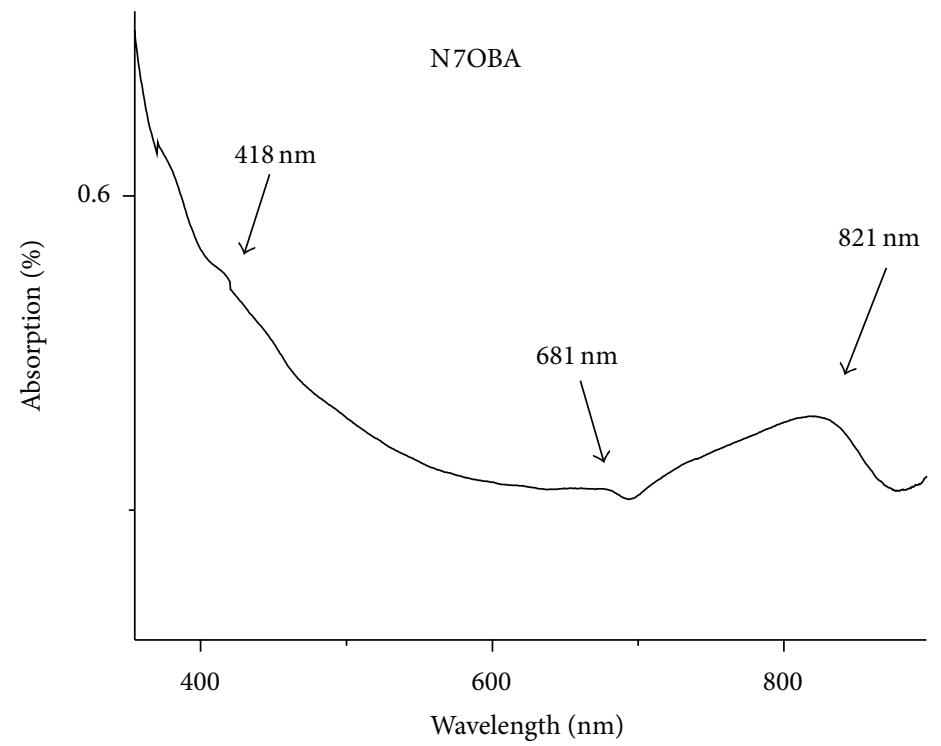

(b)

FIGURE 3: UV-visible spectrum of (a) pure and (b) nanodoped samples of 7OBA mesogens.

constant at reference temperature $\left(50^{\circ} \mathrm{C}\right)$. The $\tau_{\varepsilon}$ value has units of parts per million per degree Celsius $\left[\mathrm{ppm} /{ }^{\circ} \mathrm{C}\right]$.

Figure 4 represents the calculated $\varepsilon^{1}$ variation using (1) as a function of frequency $(f)$ for pure and nanodoped LCs compounds in different phases. $n \mathrm{OBA}$ and $\mathrm{N} n \mathrm{OBA}$ series have shown the same path in the graphical chart showing a decrease in $\varepsilon^{1}$ at low frequencies and almost constant $\varepsilon^{1}$ at high frequencies. It infers that doping ferroelectric nanoparticles to liquid crystal for a small amount $(0.1 \%)$ has affected slightly the dielectric properties of the system at low frequencies.

At high frequency, both compounds exhibit constant $\varepsilon^{1}$ and also show lower values. These are associated with the lowest electrical loss characteristics. The high orientation of liquid crystal molecules in isotropic phase shows high value of $\varepsilon^{1}$ when compared with another phase. On doping nanoparticles, the strong anchoring forces developed among nanoparticles and liquid crystal molecules caused decrease in dielectric permittivity. Fixed orientations of molecules have brought low values in liquid crystalline phase.

More stability in the dielectric constant at temperatures for high frequencies is significantly relative to low frequencies for both compounds as shown in Figure 5. $\tau_{\varepsilon}$ is the product of thermal and dielectric constant; properties of the results produced by $\tau_{\varepsilon}$ as a function of frequency are corresponding to variations in dielectric constant and structural properties.

The lower values of $\tau_{\varepsilon}$ closer to zero indicate stable dielectric constant with temperature. While compared with dielectric constant variation of pure and nano LCs, the $\tau_{\varepsilon}$ variation is high since it consists of important role of thermal and alignment stabilities with respect to applied field. From Figure 5 ( $n=3$ and 8 ), the instability thermal properties showing high value of $\tau_{\varepsilon}$ are observed for $n=3$ to 6 (both $n \mathrm{OBA}$ and $\mathrm{N} n \mathrm{OBA}$ ) mesogens at lower frequencies. The high transition temperatures and orientational order of 

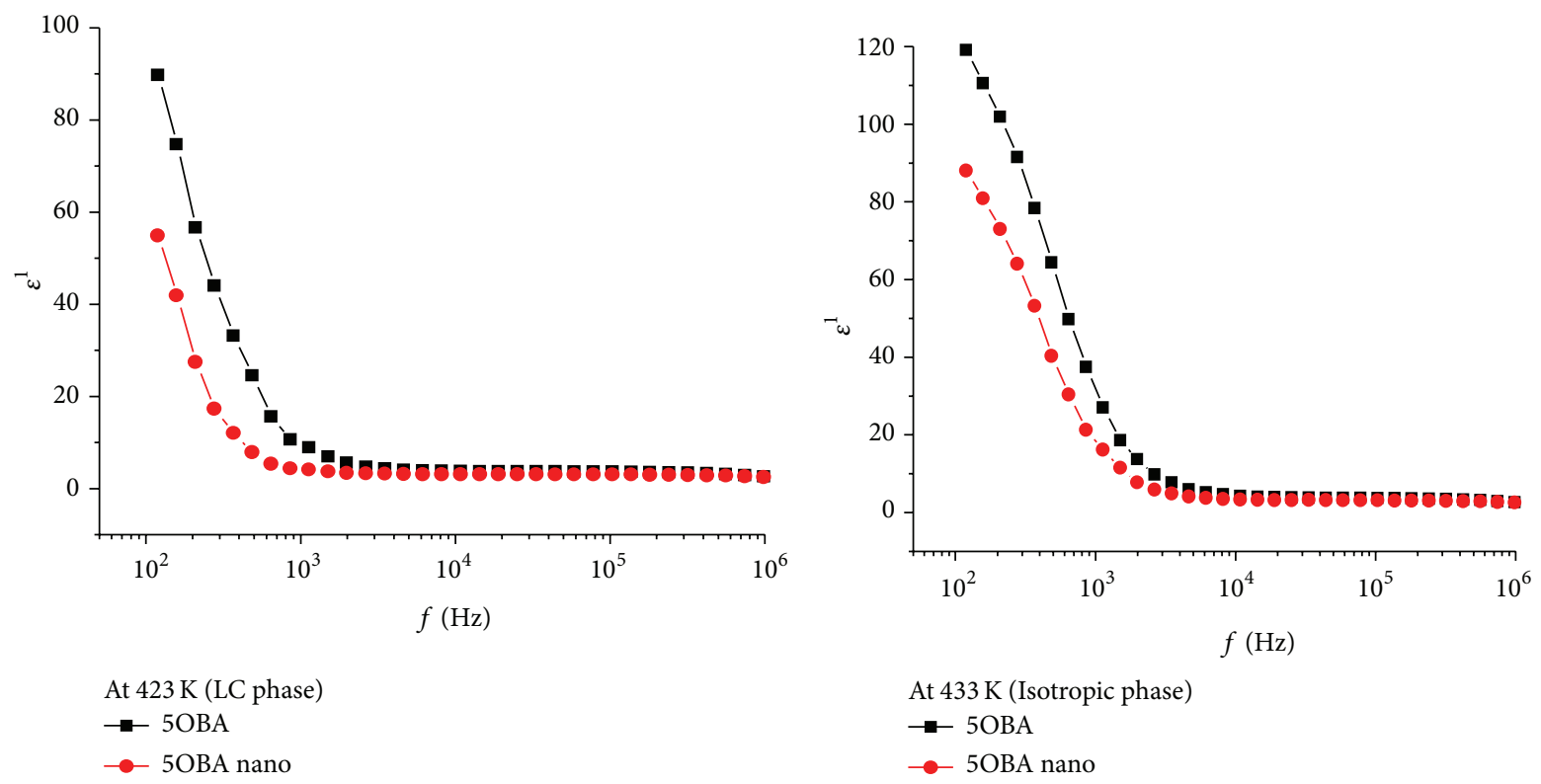

(a)

(b)

FIGURE 4: Frequency dependence of $\varepsilon^{1}$ for pure and nanodoped LCs (0.1\%) in LC and isotropic phases.

the nematic molecules are attributed to that property as a result of the dominating frequency applied. With increasing chain length, the smectic translation order decreased in the transition temperatures. Surface anchoring by nanoparticles would also bring instability in thermal and dielectric properties resulting in decrease for owing molecules aligned with respect to applied high frequencies.

\subsubsection{Frequency Dependence of Dielectric Loss, Conductivity,} and Activation Energy. The simplest model for a capacitor with a lossy dielectric is the capacitor with a perfect dielectric in parallel with a resistor giving power dissipation. The dielectric loss angle $(\tan \delta)$ values are directly measured from the experimental technique, and the imaginary part of permittivity (dielectric loss, $\varepsilon^{11}$ ) is calculated using (3) for the chosen series:

$$
\varepsilon^{11}=\varepsilon^{1} \tan \delta
$$

Based on $\varepsilon^{11}$ data, the sample conductivity $\sigma$ (siemens per meter) is estimated using (4). Changes in electrical conductivity and charge transferring for low concentration dispersion of $\mathrm{Fe}_{3} \mathrm{O}_{4}$ nanodoped in alkyloxybenzoic acids and for pure compounds are studied. At different temperatures and isotropic phase, the ac conductivity in the LC region is measured from (4) from $1 \mathrm{kHz}$ to $1 \mathrm{MHz}$ frequencies:

$$
\sigma_{\mathrm{ac}}=2 \pi \varepsilon_{o} \varepsilon^{11} f
$$

where $\varepsilon_{0}=$ permittivity of free space $8.85 \times 10^{-12} \mathrm{Fm}^{-1}, f=$ corresponding frequency in $\mathrm{Hz}$, and $\varepsilon^{11}=$ dielectric loss.

The most widely adopted form of the Arrhenius equation [27] to study for the effect of temperature on conductivity is shown in (5). The activation energy is viewed as an energetic threshold for a fruitful electric field production generated by the LC molecules orientation or by dispersed nanoparticles structure. It is possible to calculate activation energy with the Arrhenius equation simply by using the conductivity at two temperatures. It would be more realistic and reliable if more data of conductivity is taken at different temperatures. Hence, by using the ac conductivity values calculated from (4) in the $\mathrm{LC}$ temperature region from $1 \mathrm{kHz}$ to $1 \mathrm{MHz}$, the activation energy $(W)$ is calculated by following

$$
\sigma_{\mathrm{ac}}=\sigma_{o} \exp \left(\frac{-W}{K T}\right)
$$

where $W=$ activation energy $\mathrm{KJ} / \mathrm{mol}, K=$ Boltzmann constant in $\mathrm{eV} / \mathrm{K}, \mathrm{T}=$ temperature relative to the conductivity value calculated using a reference temperature and the temperature values at corresponding phases, $\sigma_{\mathrm{ac}}=$ conductivity in LC phase, and $\sigma_{o}=$ conductivity in the isotropic phase at different frequencies.

Figure 6 has indicated the dielectric loss for nanodoped system that is increased when compared to pure compounds (LC phase) because of more conducting nature in nanodoped particles. Low dielectric loss at high frequencies has shown similarity with the variation of dielectric constant (Figure 4) owing to smaller angle of rotation. The loss factor on frequency dependent is also the same behavior in a similar way as the dielectric constant (which is known when the loss experimental data is analyzed). The positional variation of relaxation peaks within the frequency range studied is observed only for a particular compound of even series of $n \mathrm{OBA}$ and NnOBA.

Figure 7 represents the conductivity variation with temperature from isotropic to crystal at specific frequencies and shows the results for 12OBA and N12OBA as a representative case. The other members of $n \mathrm{OBA}$ and $\mathrm{N} n \mathrm{OBA}$ 


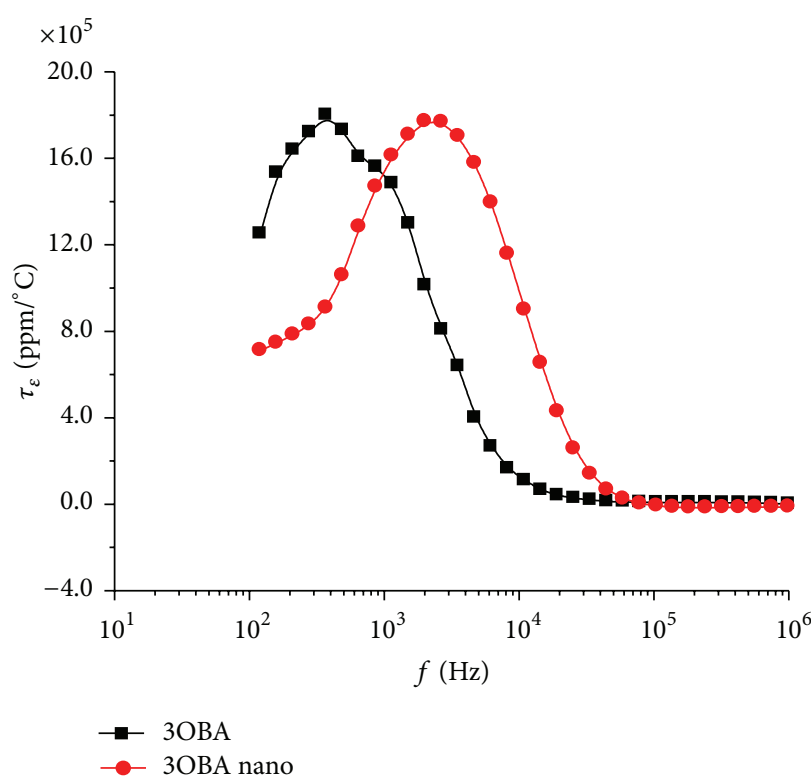

(a)

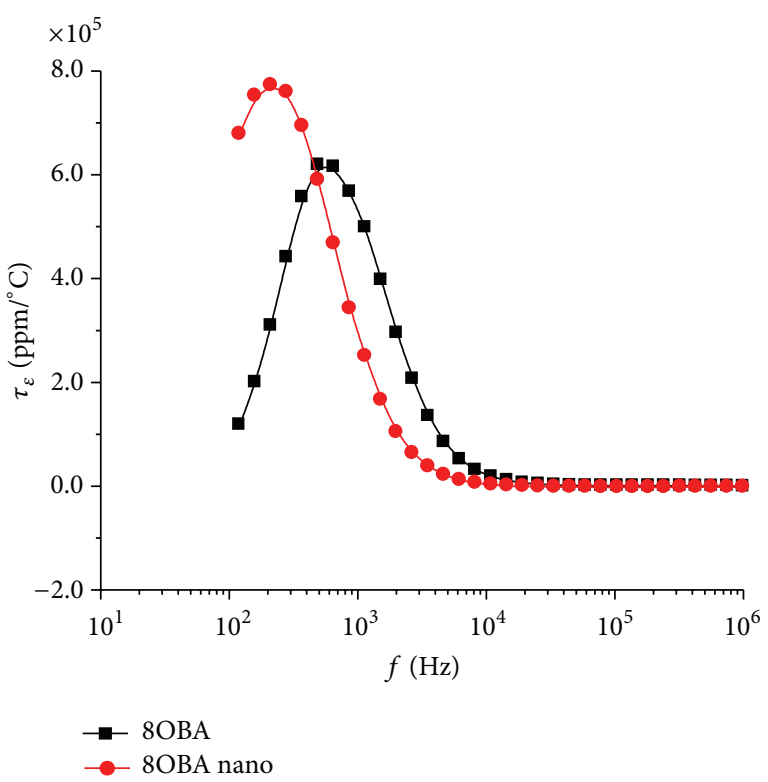

(b)

FIGURE 5: Frequency dependence of thermal coefficient of dielectric constant $\tau_{\varepsilon}$ for pure and nanodoped LCs.

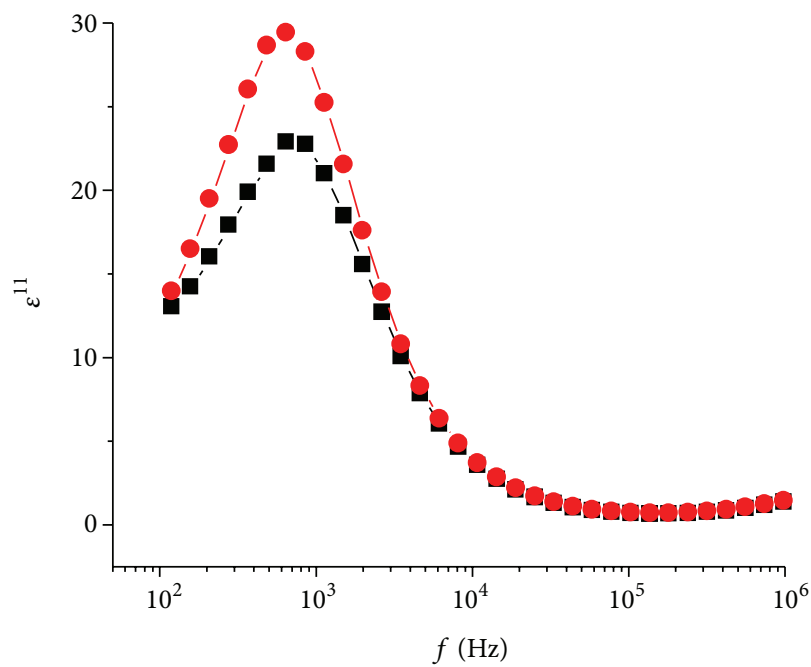

At $388 \mathrm{~K}$ (LC phase)

$\rightarrow$ 10OBA

$\rightarrow$ 10OBA nano

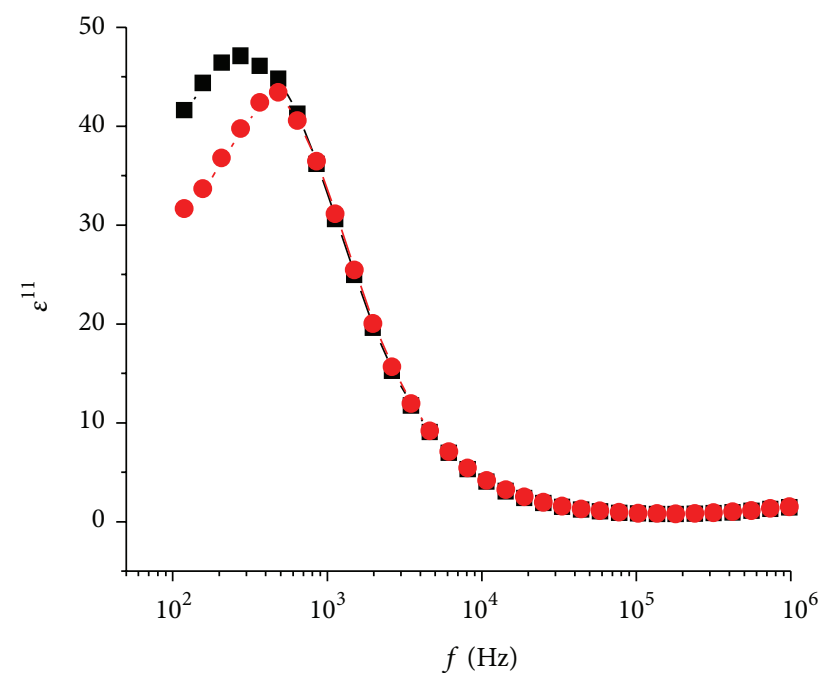

At $410 \mathrm{~K}$ (Isotropic phase)

$\rightarrow$ - 10OBA

$\rightarrow$ 10OBA nano

(a)

(b)

FIGURE 6: Frequency dependence of $\varepsilon^{11}$ for pure and (0.1\%) nanodoped LCs.

mesogens have been shown in a similar pattern but with a different magnitude. For the frequency increased from $12.3 \mathrm{~Hz}$ to $1 \mathrm{MHz}$, the conductivity rapidly increased. Hence, the variation at lower frequencies is not significant in the graph. However, the low frequencies variation is prominent for both 12OBA and N12OBA compounds as depicted on right side graph. The conductivity has increased with the increased frequency of $1 \mathrm{MHz}$. The maximum conductivity values studied at $1 \mathrm{MHz}$ are $1.25 \times 10^{-4}(\mathrm{~S} / \mathrm{m})$ in isotropic state for nanodoped LCs N3OBA and $1.07 \times 10^{-4}(\mathrm{~S} / \mathrm{m})$ for 3OBA. Having the lowest carbon chain length in the series, the mobility of molecular rotation in 3OBA has led to increase in flow of current in anisotropic LCs matrix compared to that in other compounds upon their gradual increased chain lengths in the series. The presence of higher conductivity for nanodoped LCs than pure compounds is known through the higher dielectric constant recorded for pure LCs than for nanodoped as shown in Figure 4. 


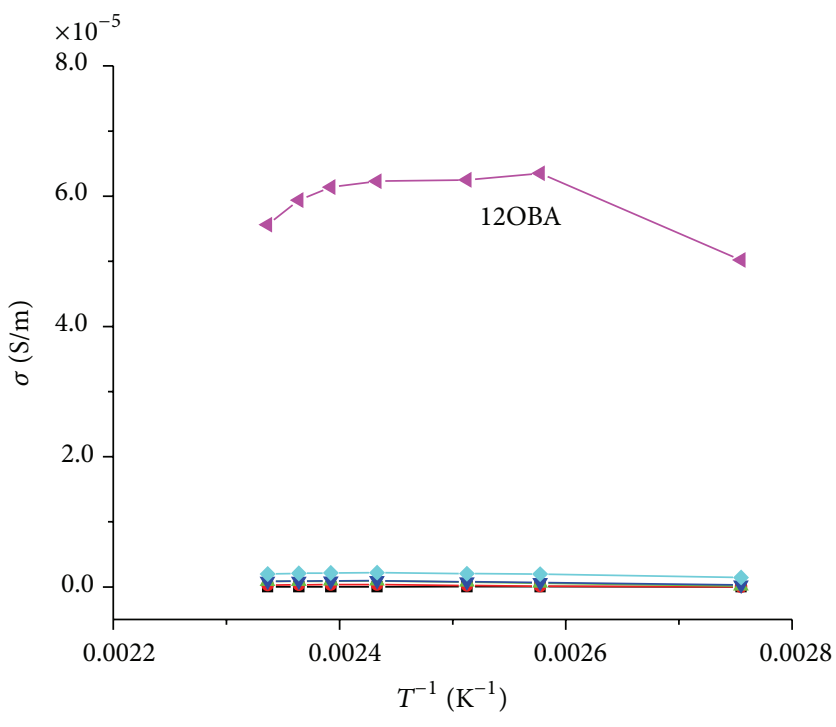

(a)

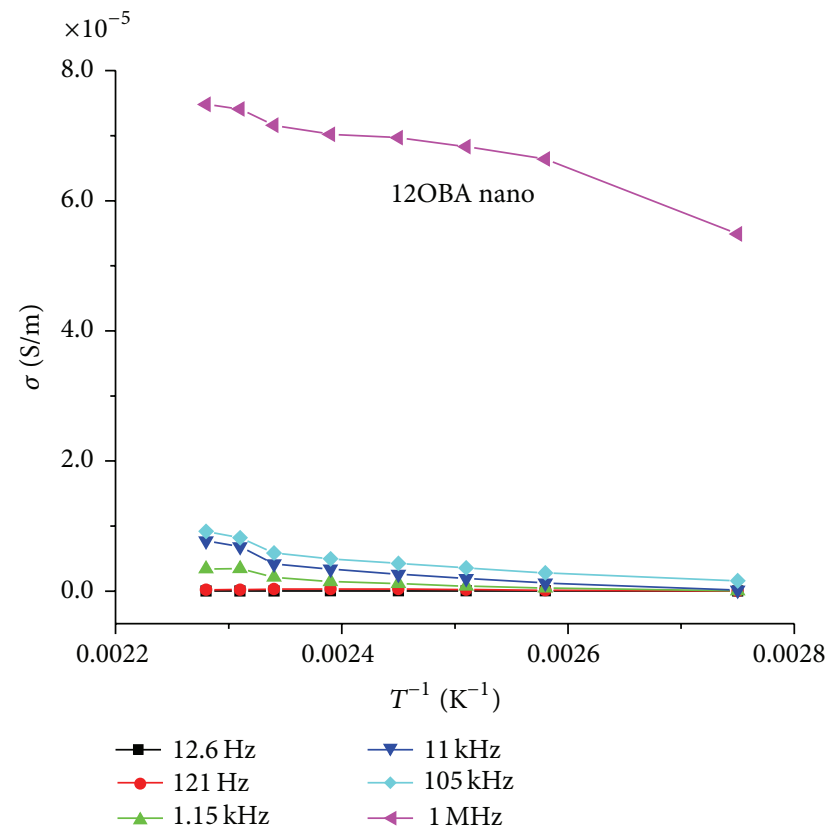

(c)

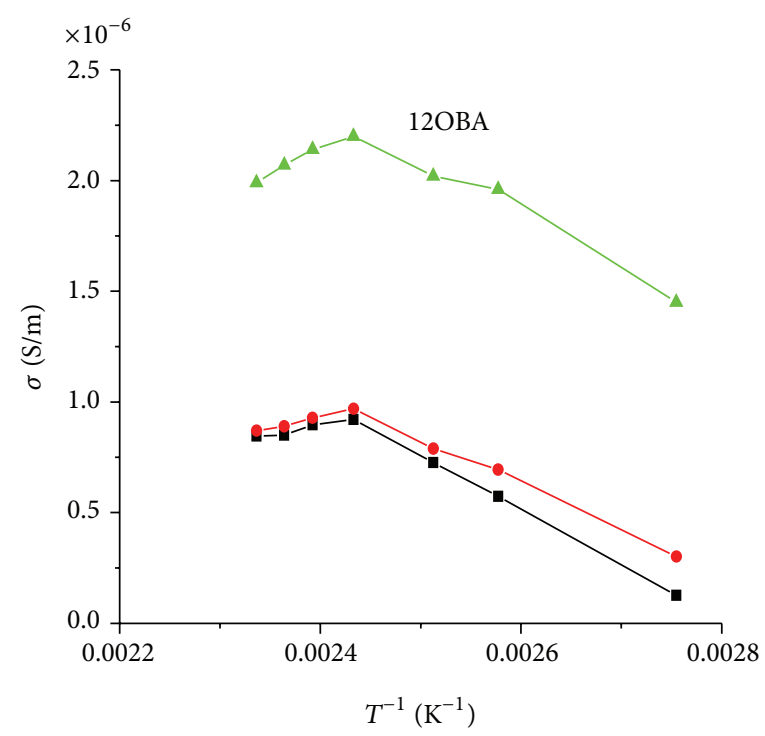

(b)

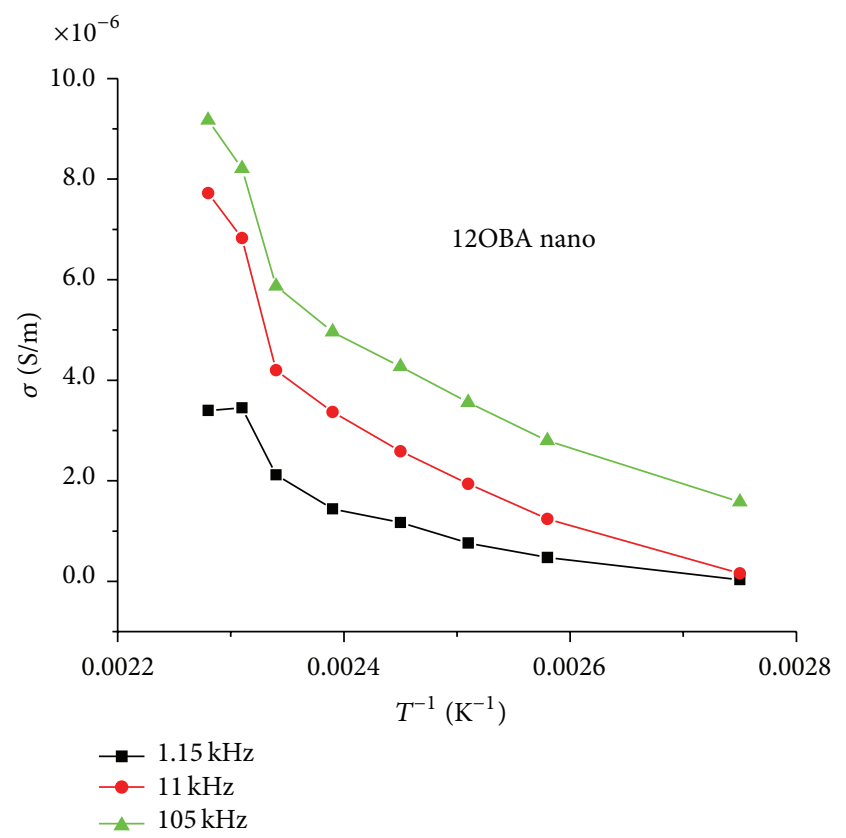

(d)

FIGURE 7: Relative conductivity $\sigma\left(\mathrm{S} \cdot \mathrm{m}^{-1}\right)$ versus inverse temperature $1 / T(1 / \mathrm{K})$ for pure and nanodoped LCs of $12 \mathrm{OBA}((\mathrm{a})$ and (c)) at various frequencies and ((b) and (d)) for the variations at low frequencies.

The anomalies at near transition temperatures are observed. A nearly invariant temperature affecting ac conductivity is noticed in the smectic to crystal transition. A sharp decrease in nematic phase is observed with respect to increase in inverse temperature. As discussed earlier, the high conductivity value is exhibited at high frequency; therefore, for pure and nanodoped LCs, high frequency relative conductivity dominates than other lower frequencies.

The calculated activation energy $(W)$ for conduction in entire LC region by using (5) as function of frequency at LC temperatures for nematic and smectic regions is shown in Figure 8. The results shown here are representing 5OBA and 8OBA and their nanocomplexes as a case study and conclusions are drawn for other members of $n$ OBA mesogens.

The activation energy also showed similar tendencies in the nanodispersed samples that is decreasing with increasing frequency in the smectic and solid phases. Figure 8 indicates that there are three levels present in the frequency range in nematic phase. Firstly, the frequency increased with the increase of activation energy; secondly, on further increase 


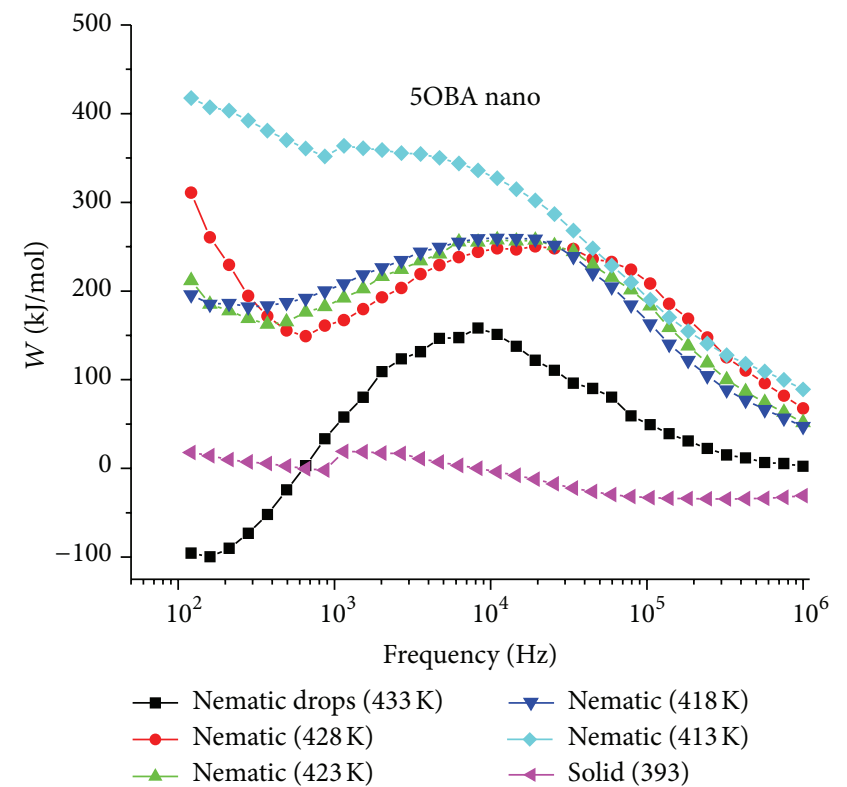

(a)

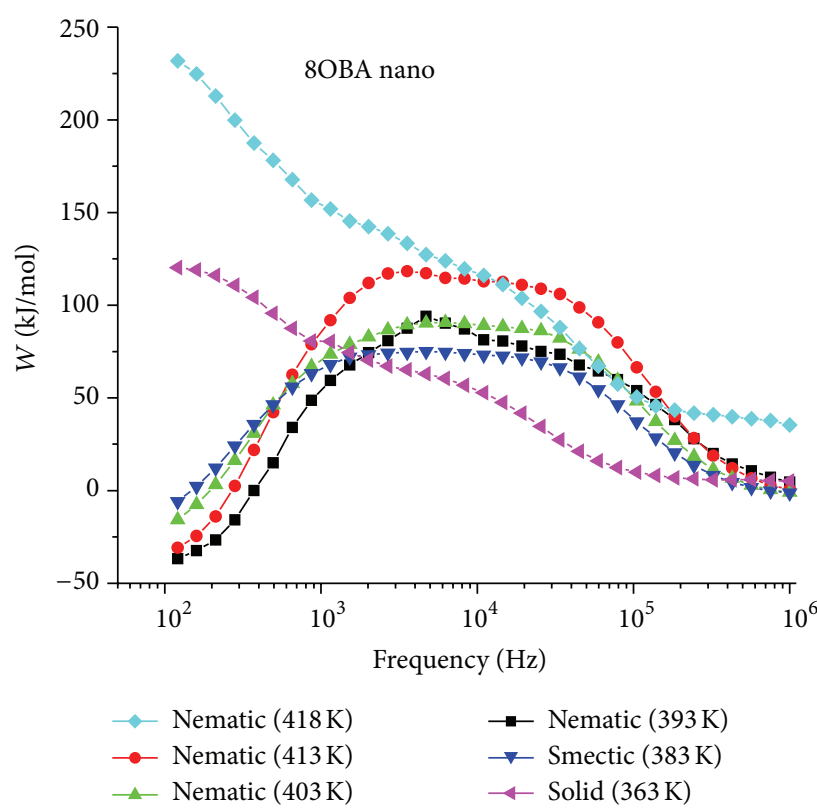

(c)

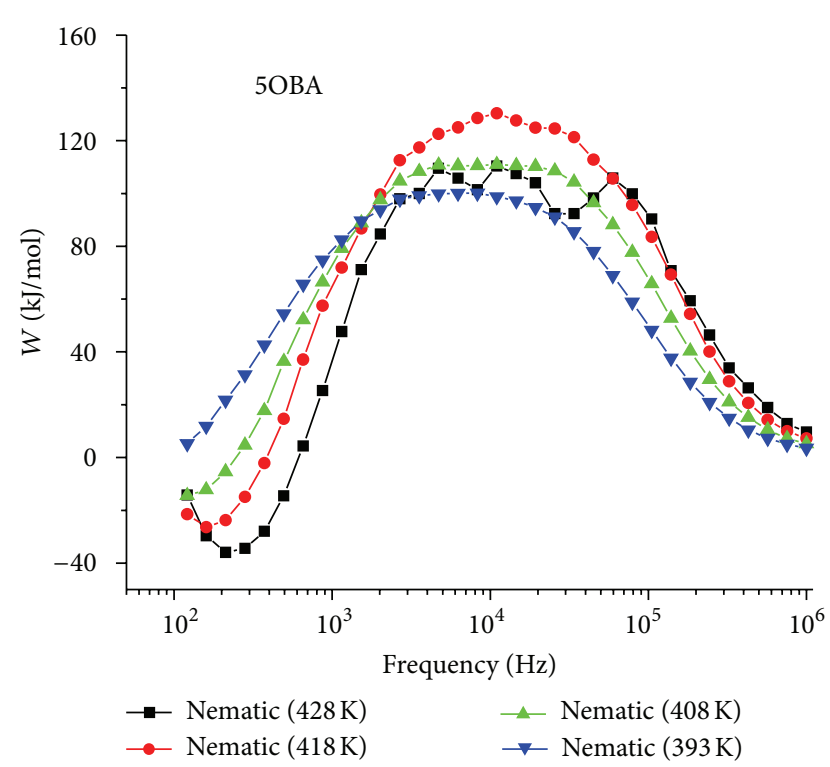

(b)

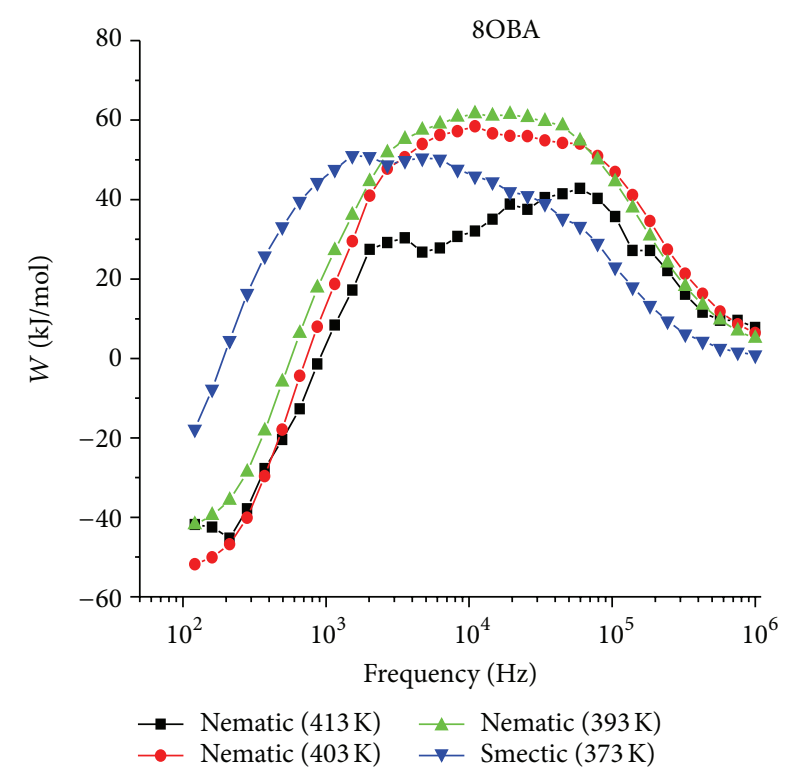

(d)

FIGURE 8: Frequency dependence of activation energy in nematic and smectic phases for (a) nanodoped and (b) pure LCs of 5OBA and (c) nanodoped $8 \mathrm{OBA}$ and pure $8 \mathrm{OBA}$.

in frequency, there exists a broad frequency region where the activation energy is nearly constant and finally started decreasing until approaching $0(\mathrm{KJ} / \mathrm{mol})$. This effect is raised due to the role of the surface activity of dispersed particles in local order of the liquid crystal as a result of elastic distortions associated with the liquid crystal on following increased frequencies.

By analyzing the activation energy results, it can be concluded that the energy values for both compounds in nematic phase are in the range from -100 to $250(\mathrm{KJ} / \mathrm{mol})$. The values of activation energy in smectic phase at a particular frequency region are more than $250(\mathrm{KJ} / \mathrm{mol})$, which is similar to the relative conductivity $(\sigma)$ that showed steep slope in nematic as in smectic phase. This can be explained by considering two reasons while using long and short molecular axis rotation in the liquid crystal matrix in the presence or absence of the suspended nanoparticles with respect to applied field. Firstly, at low frequencies, the increase in activation energy in nematic phase for $n=3$ to 6 (both pure and nano) has led to restricted mobility of charged carriers resulting in low conductivity (Figure 7). At higher frequencies, the decrease in the activation energy (Figure 8) is related to high mobility of 


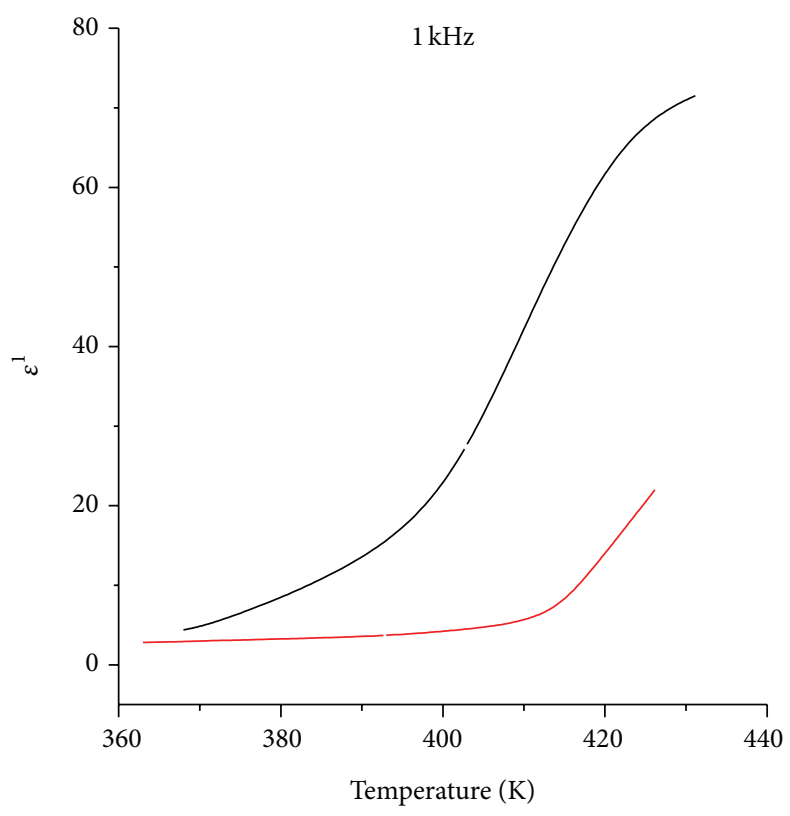

(a)

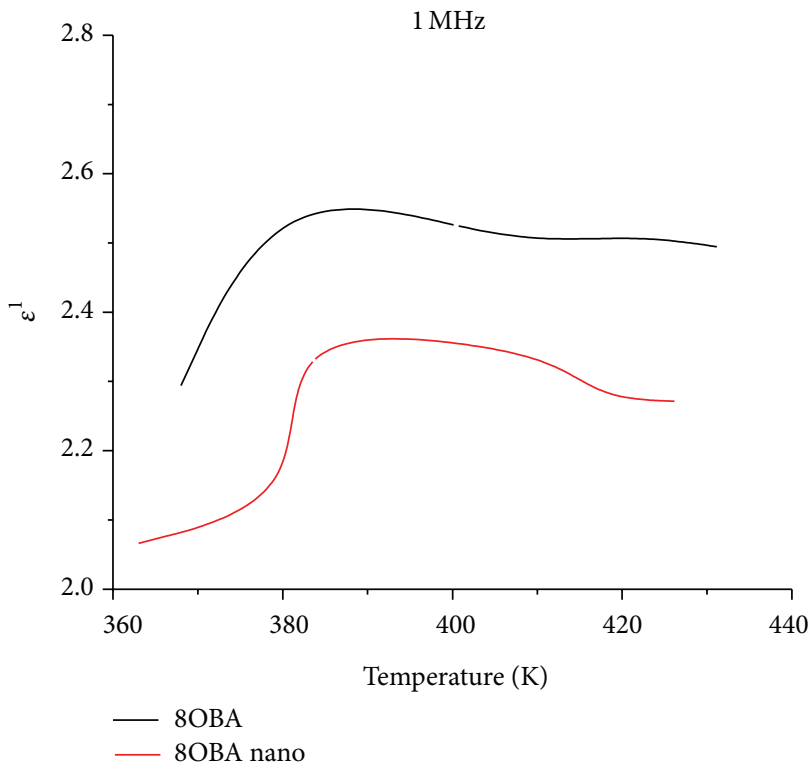

(c)

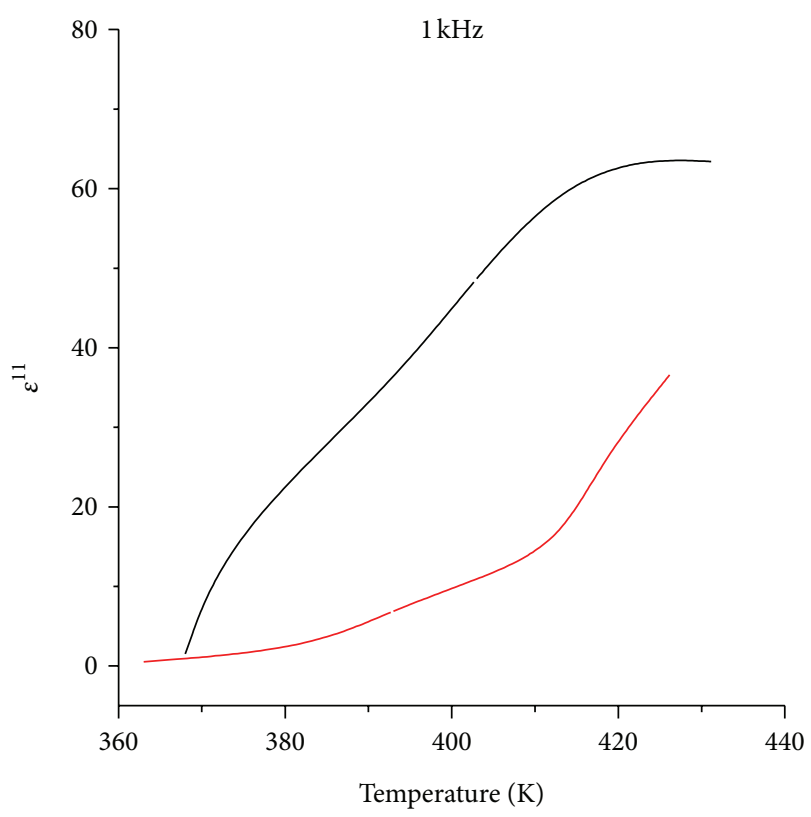

(b)

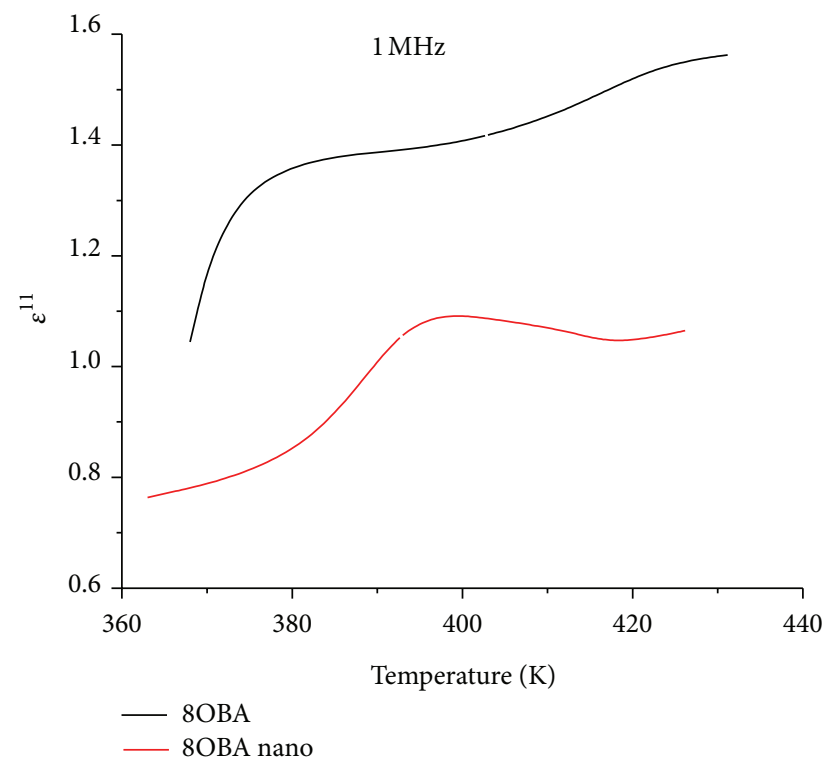

(d)

Figure 9: Temperature dependence of $\varepsilon^{1}$ and $\varepsilon^{11}$ for (a) nanodoped and (b) pure $8 \mathrm{OBA}$ at $1 \mathrm{kHz}$ and (c) nanodoped and (d) pure at $1 \mathrm{MHz}$.

charged transports. This is confirmed by correlating the high conductivity (Figure 7) and low temperature coefficient of dielectric constant (Figure 5) at higher frequencies. Therefore, the distortion in rotation and in alignment of LC molecules with respect to the field will bring on increase in the conductivity on lowering its active potential energy.

3.2.3. Temperature Dependence of Dielectric Constant and Loss for Pure and Nanodoped Alkyloxybenzoic Acids. Temperature dependent dielectric studies for the prepared $n$ OBA nanodoped particles are carried out to analyze its response to an applied low ac voltage $(2 \mathrm{~V})$. The variations in dielectric constant and loss with temperature at various frequencies are shown in Figure 9. Increase in the ionization of the sample with temperature increases the processes of conductivity and dissipation factor simultaneously, and it is vice versa in case of higher frequencies.

A nearly similar trend of dielectric constant with temperature is also observed in dielectric loss. These different variations at low and high frequencies due to temperature may be attributed to conformational vibrations of mobile molecular fragments, like vibrations of flexible alkyloxy groups and vibrations of the benzene rings together of $n$ OBA mesogens. From Figure 9(a) $(1 \mathrm{kHz})$, it is observed that an increase 


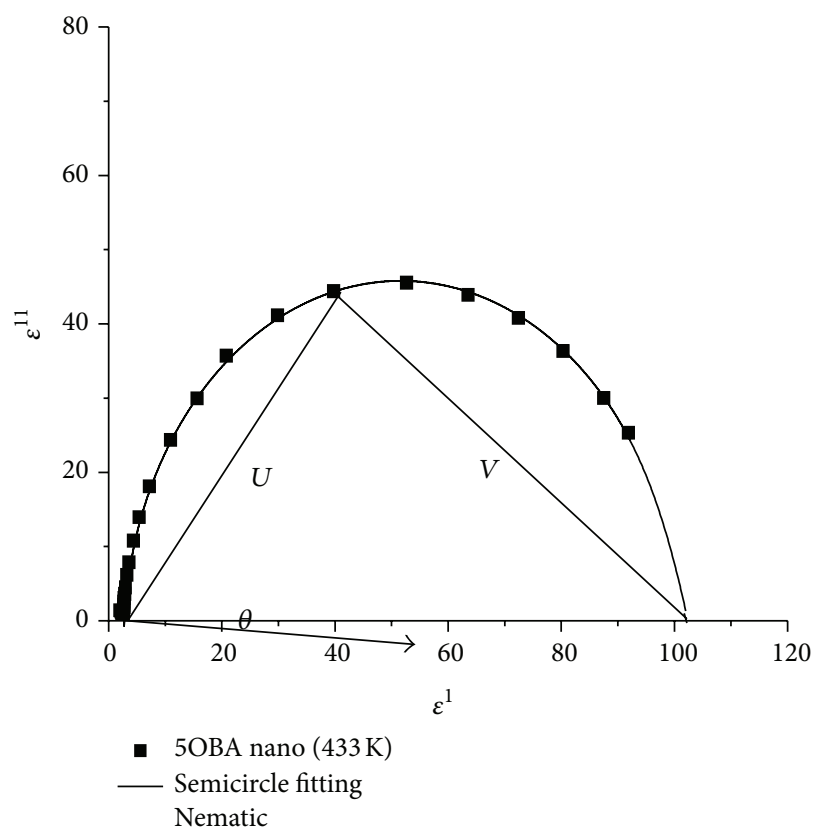

(a)

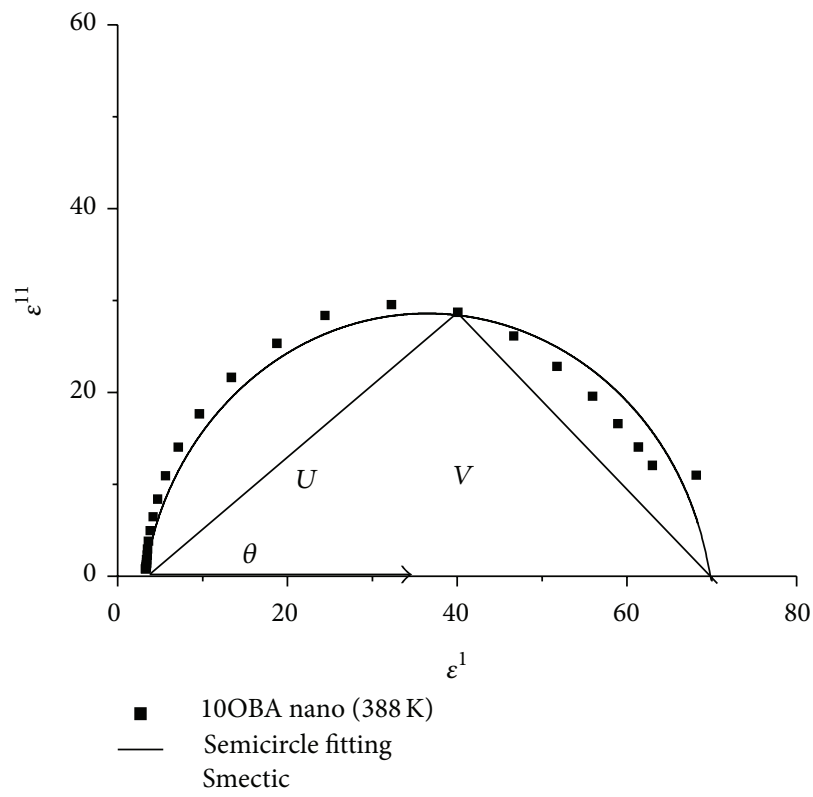

(c)

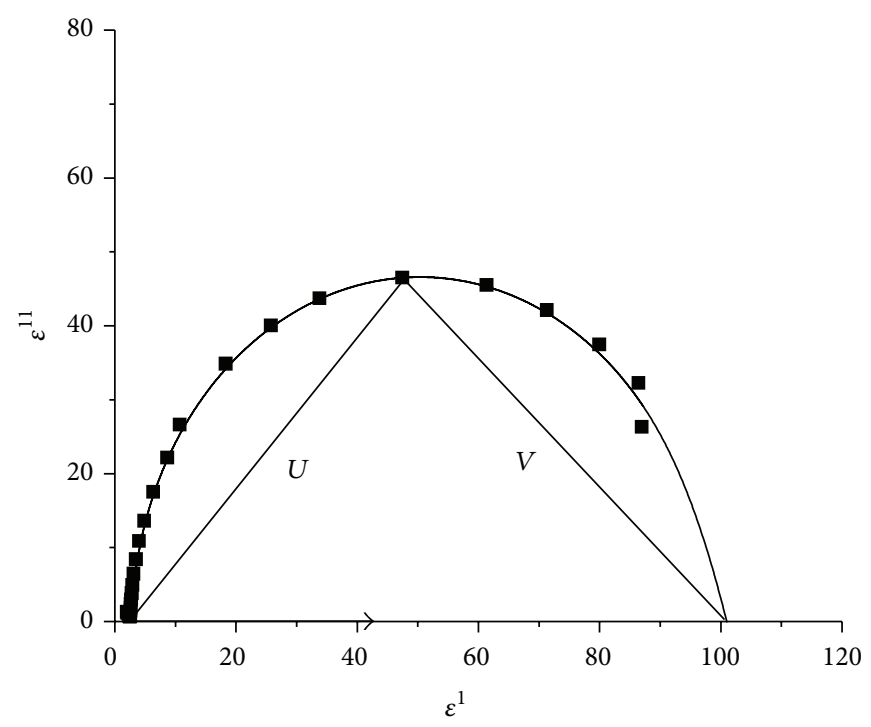

- 5OBA nano ( $428 \mathrm{~K})$

Semicircle fitting

Nematic

(b)

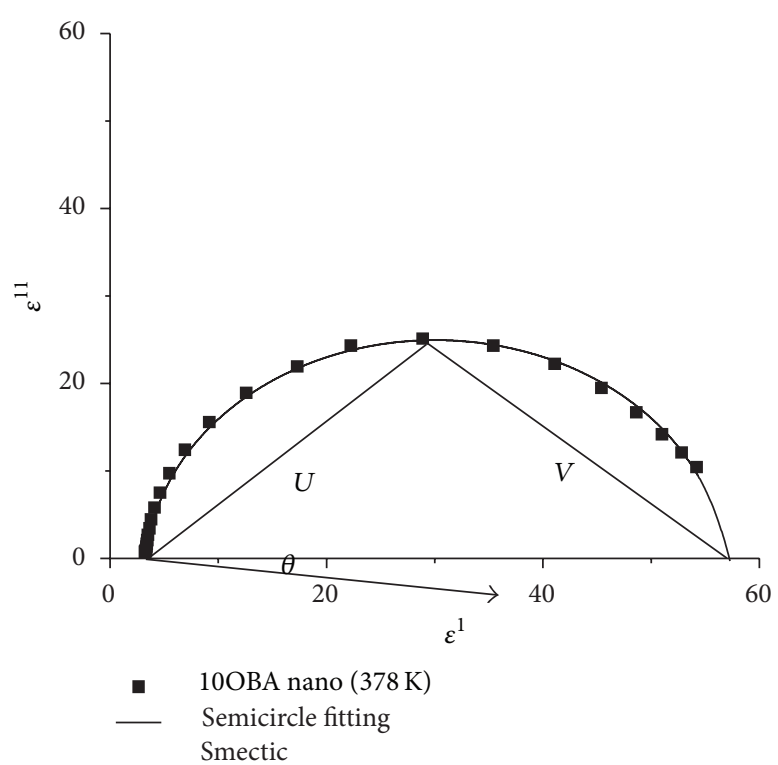

(d)

Figure 10: Cole-Cole plots of $\varepsilon^{1}$ and $\varepsilon^{11}$ for nematic and smectic phases of NnOBA at different temperatures; N5OBA (nematic, (a) and (b)) and N10OBA (smectic, (c) and (d)) compounds.

in dielectric constant on increasing temperature has suggested that the dipoles are oriented perpendicularly towards the director at high temperatures, whereas in Figure 9(b) $(1 \mathrm{MHz})$, nearly, constant is observed at high temperatures. The difference in dielectric constant and loss of pure and nanodoped LCs as shown in Figure 9 is due to variations in thermal transition temperatures.
3.2.4. Cole-Cole Plots of $\varepsilon^{1}$ and $\varepsilon^{11}$ for Nematic and Smectic Phases between $1 \mathrm{kHz}$ to $1 \mathrm{MHz}$ for Pure and Nanodoped $p-n$ Alkyloxybenzoic Acids. By using the dielectric data (dielectric constant and loss) from LCR meter, the Cole-Cole plots [28] are drawn for different temperatures. The relaxation time $\tau$ (Sec) can be found from the arc plot by using

$$
\omega=\left(\frac{v}{u}\right)^{1 /(1-\alpha)},
$$


where $\alpha=\theta / 90$ (distribution parameter), $\omega=2 \Pi f$ (angular frequency, $\mathrm{Hz}$ ), and $u, v$ values are determined from the drawn Cole-Cole plots.

Figure 10 (as representative case) illustrates a few characteristic results showing typical Cole-Cole plots at several temperatures (in LC region). The symbols used in it are representing the experimental data and the solid line is representing the semicircle fitting. Table 2 provides the subset relaxation time values at different frequencies and phases. Same relaxation times are observed to all frequencies on semicircle curvature at a particular temperature on varied $u, v$ values. From Figure 10, conclusions are drawn that the dielectric dispersions (curvature) for nanodoped LCs are exhibited better at the frequency studied when compared to pure composites. These plots are drawn to analyze the dielectric dispersion spectra of the LC phases with respect to isotropic phase relaxation times and variations in dipoles orientation variation as a function of temperature. Even though there is a fixed temperature and having same nematic or smectic order with same molecular structure in these series, there are different relaxation times observed at different relaxation frequencies for variation in their carbon chain length. Table 2 shows the calculated values of relaxation times using Cole-Cole plots in isotropic, nematic, and smectic phases at particular temperatures.

Among all these series, the pure 7OBA compound does not show any relaxation but the 7OBA nanodoped compound shows relaxation. This phenomenon is reversed in the case of 4OBA compound as given in Table 2. It is concluded that the $\mathrm{Fe}_{3} \mathrm{O}_{4}$ particles hindered the free rotations in the liquid crystal matrix and showed better relaxation times at studied frequencies when compared to pure compounds. In some cases of pure and nanodoped LCs, have displayed nearly equal dispersions and relaxation times as that of the isotropic phase [12] and showing the reorientation of molecular dipoles dominating the ordering in LC phases. The presence of nano not only effected the molecular ordering but also influenced the dielectric parameters like $\varepsilon^{\prime}, \varepsilon^{\prime \prime}, \tau$, and activation energy. These changes can be attributed to the dipole moment contribution of magnetite nanoparticles to the liquid crystal molecules $[29,30]$.

\section{Conclusions}

The dielectric spectrum of frequency dependent dielectric constant and the loss for both pure and nanodoped alkyloxybenzoic acids in perpendicular alignment are analyzed. The sharp changes in measured dielectric parameters in the temperature region are corresponding to the respective phase transitions in the liquid crystal materials. Two regions of dispersion observed on dielectric charts, that is, one at low frequency dispersion and the other at high-frequency, are related to the rotation of molecules about the short axis in the former case and about the long axis in the latter case. In addition, the variation in activation energy at different regions of temperature corresponds to conductivity as a function of frequency. The strong interaction between the $\mathrm{Fe}_{3} \mathrm{O}_{4}$ nanoparticles and the liquid crystal anisotropic
TABLE 2: Subset values of relaxation time (Sec) with temperature variation at different frequencies for $n \mathrm{OBA}$.

\begin{tabular}{|c|c|c|}
\hline \multirow[t]{2}{*}{ Phases } & \multicolumn{2}{|c|}{ Relaxation times (frequency $(\mathrm{Hz}))(\mathrm{Sec})$} \\
\hline & Propyloxybenzoic acids & $\begin{array}{c}\text { Nanopropyloxybenzoic } \\
\text { acids }\end{array}$ \\
\hline Isotropic & $0.185 \times 10^{-3}\left(8.69 \times 10^{2}\right)$ & $0.191 \times 10^{-4}\left(11.0 \times 10^{3}\right)$ \\
\hline \multirow[t]{2}{*}{ Nematic } & $0.116 \times 10^{-4}\left(1.46 \times 10^{4}\right)$ & $0.311 \times 10^{-2}\left(8.69 \times 10^{2}\right)$ \\
\hline & Butyloxybenzoic acids & $\begin{array}{l}\text { Nanobutyloxybenzoic } \\
\text { acids }\end{array}$ \\
\hline \multirow[t]{2}{*}{ Nematic } & $0.227 \times 10^{-3}\left(1.15 \times 10^{3}\right)$ & - \\
\hline & Pentyloxybenzoic acids & $\begin{array}{l}\text { Nanopentyloxybenzoic } \\
\text { acids }\end{array}$ \\
\hline Isotropic & $0.183 \times 10^{-3}\left(8.69 \times 10^{2}\right)$ & $0.192 \times 10^{-3}\left(8.69 \times 10^{2}\right)$ \\
\hline \multirow[t]{2}{*}{ Nematic } & $0.116 \times 10^{-4}\left(1.46 \times 10^{4}\right)$ & $0.131 \times 10^{-3}\left(1.21 \times 10^{2}\right)$ \\
\hline & Hexyloxybenzoic acids & $\begin{array}{l}\text { Nanohexyloxybenzoic } \\
\text { acids }\end{array}$ \\
\hline Isotropic & $0.245 \times 10^{-3}\left(8.69 \times 10^{2}\right)$ & $0.100 \times 10^{-2}\left(1.60 \times 10^{2}\right)$ \\
\hline \multirow[t]{2}{*}{ Nematic } & $0.251 \times 10^{-3}\left(4.94 \times 10^{2}\right)$ & $0.126 \times 10^{-2}\left(1.60 \times 10^{2}\right)$ \\
\hline & Heptyloxybenzoic acids & $\begin{array}{l}\text { Nanoheptyloxybenzoic } \\
\text { acids }\end{array}$ \\
\hline Isotropic & - & $0.562 \times 10^{-3}\left(2.81 \times 10^{2}\right)$ \\
\hline \multirow[t]{2}{*}{ Nematic } & - & $0.125 \times 10^{-2}\left(2.21 \times 10^{2}\right)$ \\
\hline & Octyloxybenzoic acids & $\begin{array}{l}\text { Nanooctyloxybenzoic } \\
\text { acids }\end{array}$ \\
\hline Isotropic & $0.138 \times 10^{-3}\left(2.02 \times 10^{3}\right)$ & $0.308 \times 10^{-3}\left(8.69 \times 10^{2}\right)$ \\
\hline Nematic & $0.227 \times 10^{-3}\left(1.15 \times 10^{3}\right)$ & $0.131 \times 10^{-2}\left(1.21 \times 10^{2}\right)$ \\
\hline \multirow[t]{2}{*}{ Smectic } & $0.131 \times 10^{-2}\left(1.21 \times 10^{2}\right)$ & $0.130 \times 10^{-2}\left(3.14 \times 10^{2}\right)$ \\
\hline & Nonyloxybenzoic acids & $\begin{array}{l}\text { Nanononyloxybenzoic } \\
\text { acids }\end{array}$ \\
\hline Isotropic & $0.995 \times 10^{-3}\left(1.60 \times 10^{2}\right)$ & $0.563 \times 10^{-3}\left(2.12 \times 10^{2}\right)$ \\
\hline Nematic & - & $0.131 \times 10^{-2}\left(1.21 \times 10^{2}\right)$ \\
\hline \multirow[t]{2}{*}{ Smectic } & - & - \\
\hline & Decyloxybenzoic acids & $\begin{array}{l}\text { Nanodecyloxybenzoic } \\
\text { acids }\end{array}$ \\
\hline Isotropic & $0.398 \times 10^{-3}\left(1.15 \times 10^{3}\right)$ & $0.426 \times 10^{-3}\left(3.73 \times 10^{2}\right)$ \\
\hline Nematic & $0.584 \times 10^{-3}\left(2.81 \times 10^{2}\right)$ & $0.312 \times 10^{-3}\left(8.69 \times 10^{2}\right)$ \\
\hline \multirow[t]{2}{*}{ Smectic } & $0.186 \times 10^{-3}\left(8.69 \times 10^{2}\right)$ & $0.224 \times 10^{-3}\left(1.53 \times 10^{3}\right)$ \\
\hline & $\begin{array}{l}\text { Dodecyloxybenzoic } \\
\text { acids }\end{array}$ & $\begin{array}{c}\text { Nanododecyloxybenzoic } \\
\text { acids }\end{array}$ \\
\hline Isotropic & $0.988 \times 10^{-3}\left(2.81 \times 10^{2}\right)$ & $0.162 \times 10^{-3}\left(2.68 \times 10^{3}\right)$ \\
\hline Nematic & $0.991 \times 10^{-3}\left(2.81 \times 10^{2}\right)$ & $0.160 \times 10^{-3}\left(2.81 \times 10^{2}\right)$ \\
\hline Smectic & $0.098 \times 10^{-2}\left(6.55 \times 10^{2}\right)$ & $0.520 \times 10^{-3}\left(2.68 \times 10^{3}\right)$ \\
\hline
\end{tabular}

matrix has brought obvious effects on thermal transition behavior and dielectric properties of LCs. Therefore, when the nanoparticles are dispersed in the anisotropic liquid crystalline medium, the particle resonance, depending on the angle of the director and the surface reactivity, is identifiable.

\section{Conflict of Interests}

The authors declare that there is no conflict of interests regarding the publication of this paper. 


\section{Acknowledgments}

The authors gratefully acknowledge UGC DRS LEVEL III Program no. F.530/1/DRS/2009 (SAP-I) dated September 02, 2009, and DST FIST Program no. DST/FST/PSI - 002/2011 dated December 20, 2011, New Delhi, for providing financial assistance to the Department of Physics, ANU.

\section{References}

[1] X. Liu, Z. Zhong, Y. Tang, and B. Liang, "Review on the synthesis and applications of $\mathrm{Fe}_{3} \mathrm{O}_{4}$ nanomaterials," Journal of Nanomaterials, vol. 2013, Article ID 902538, 7 pages, 2013.

[2] E. SaievarIranizad, Z. Dehghani, and M. Nadafan, "Measurement of ferronematic liquid crystal using a single beam method," International Journal of Engineering Research and Science and Technology, vol. 3, no. 2, pp. 1043-1047, 2014.

[3] J. Mazo-Zuluaga, J. Restrepo, and J. Mejía-López, "Surface anisotropy of a $\mathrm{Fe}_{3} \mathrm{O}_{4}$ nanoparticle: a simulation approach," Physica B: Condensed Matter, vol. 398, no. 2, pp. 187-190, 2007.

[4] R. M. Cornell and U. Schwertmann, The Iron Oxides, VCH mbH, Weinheim, Germany, 1996.

[5] M. Ramakrishna, N. Rao, P. V. D. Prasad, and V. G. K. M. Pisipati, "Orientational order parameter in alkoxy benzoic acids-optical studies," Molecular Crystals and Liquid Crystals, vol. 528, pp. 49-63, 2010.

[6] H. P. Hinov and M. Petrov, "Observations of Sm C layer undulations and Sm C edge-dislocations in NOBA films," Molecular crystals and liquid crystals, vol. 100, no. 3-4, pp. 223251, 1983.

[7] V. N. Vijayakumar, K. Murugadass, and M. L. N. Madhu Mohan, "Inter hydrogen bonded complexes of hexadecylaniline and alkoxy benzoic acids: a study of crystallization kinetics," Brazilian Journal of Physics, vol. 39, no. 3, pp. 600-605, 2009.

[8] T. Chitravel and M. L. N. M. Mohan, "Occurrence of ambient temperature and reentrant smectic ordering in an intermolecular hydrogen bonding between alkyl aniline and alkoxy benzoic acids," Molecular Crystals and Liquid Crystals, vol. 524, no. 1, pp. 131-143, 2010.

[9] P. A. Kumar, V. G. K. M. Pisipati, A. V. Rajeswari, and S. S. Sastry, "Induced smectic-G phase through intermolecular hydrogen bonding - part XII: thermal and phase behaviour of p-aminobenzonitrile: p-n-alkoxybenzoic acids," Zeitschrift für Naturforschung A: Journal of Physical Sciences, vol. 57, no. 3-4, pp. 184-188, 2002.

[10] L. Bata and G. Molnár, "Dielectric dispersion measurements in a nematic liquid crystal mixture," Chemical Physics Letters, vol. 33, no. 3, pp. 535-539, 1975.

[11] A. V. Koval'chuk, "Relaxation processes and charge transport across liquid crystal-electrode interface," Journal of Physics Condensed Matter, vol. 13, no. 46, pp. 10333-10345, 2001.

[12] A. V. Koval'chuk, "Low-frequecy dielectric relaxation at the tunnel charge transfer across the liquid/electrode interface," Functional Materials, vol. 8, no. 4, pp. 690-693, 2001.

[13] O. P. Gornitska, A. V. Kovalchuk, T. N. Kovalchuk et al., "Dielectric properties of nematic liquid crystals with $\mathrm{Fe}_{3} \mathrm{O}_{4}$ nanoparticles in direct magnetic field," Semiconductor Physics, Quantum Electronics and Optoelectronics, vol. 12, no. 3, pp. 309314, 2009.

[14] H. H. Liang and J. Y. Lee, "Enhanced electro-optical properties of liquid crystals devices by doping with ferroelectric nanoparticles," in Ferroelectrics-Material Aspects, M. Lallart, Ed., chapter 10, InTech, Rijeka, Croatia, 2011.

[15] M. J. Park and O. O. Park, "Alignment of liquid crystals on a topographically nano-patterned polymer surface prepared by a soft-imprint technique," Microelectronic Engineering, vol. 85, no. 11, pp. 2261-2265, 2008.

[16] G. W. Gray, Molecular Structure and the Properties of Liquid Crystals, Academic Press, New York, NY, USA, 1962.

[17] R. Pavlis, Kansas USA edition of Micscape Magazine, Microscopy UK Front Page, 2006.

[18] S. S. Sastry, S. S. Begum, T. V. Kumari, V. R. K. Murthy, and S. T. Ha, "Effect of magnetite nano particles on $p$ - $n$-alkyl benzoic acid mesogens," E-Journal of Chemistry, vol. 9, no. 4, pp. 24622471, 2012.

[19] H. Stark, "Physics of colloidal dispersions in nematic liquid crystals," Physics Report, vol. 351, no. 6, pp. 387-474, 2001.

[20] R. W. Ruhwandl and E. M. Terentjev, "Long-range forces and aggregation of colloid particles in a nematic liquid crystal," Physical Review E-Statistical Physics, Plasmas, Fluids, and Related Interdisciplinary Topics, vol. 55, no. 3, pp. 2958-2961, 1997.

[21] F. S. Y. Yeung, Y. L. J. Ho, Y. W. Li, and H. S. Kwok, "Liquid crystal alignment layer with controllable anchoring energies," Journal of Display Technology, vol. 4, no. 1, pp. 24-27, 2008.

[22] K. Vijayalakshmi, Induced smectic phases through hydrogen bonded mesogenic systems [Ph.D. thesis], Acharya Nagarjuna University, Andhra Pradesh, India, 2009.

[23] S. Deepthi and C. R. S. Kumar, "Molecular dynamics of mesogenic p- $n$-alkoxy benzoic acid," International Journal of Advanced Research, vol. 2, no. 2, pp. 30-34, 2014.

[24] M. Petrov, E. Keskinova, and B. Katranchev, "The electroconvection in the nematic liquid crystals with short range smectic C order," Journal of Molecular Liquids, vol. 138, no. 1-3, pp. 130$138,2008$.

[25] A. K. Mishra and D. Das, "Investigation on Fe-doped $\mathrm{ZnO}$ nanostructures prepared by a chemical route," Materials Science and Engineering B: Solid-State Materials for Advanced Technology, vol. 171, no. 1-3, pp. 5-10, 2010.

[26] D. C. Thompson, M. M. Tentzeris, and J. Papapolymerou, "Packaging of MMICs in multilayer LCP substrates," IEEE Microwave and Wireless Components Letters, vol. 16, no. 7, pp. 410-412, 2006.

[27] S. Arrhenius, "Uber die reaktionsgeschwindigkeit bei der inversion von rohrzucker durch säuren," Journal of Physical Chemistry, vol. 4, pp. 226-248, 1889.

[28] K. S. Cole and R. H. Cole, "Dispersion and absorption in dielectrics I. Alternating current characteristics," Journal of Chemical Physics, vol. 9, no. 4, pp. 341-351, 1941.

[29] A. Thanassoulas, E. Karatairi, C. George et al., "CdSe nanoparticles dispersed in ferroelectric smectic liquid crystals: effects upon the smectic order and the smectic- $A$ to chiral smectic- $C$ phase transition," Physical Review E-Statistical, Nonlinear, and Soft Matter Physics, vol. 88, Article ID 032504, 8 pages, 2013.

[30] M. Petrov, B. Katranchev, P. M. Rafailov et al., "Phase and properties of nanocomposites of hydrogen bonded liquid crystals and carbon nanotubes," Physical Review E-Statistical, Nonlinear, and Soft Matter Physics, vol. 88, Article ID 042503, 11 pages, 2013. 

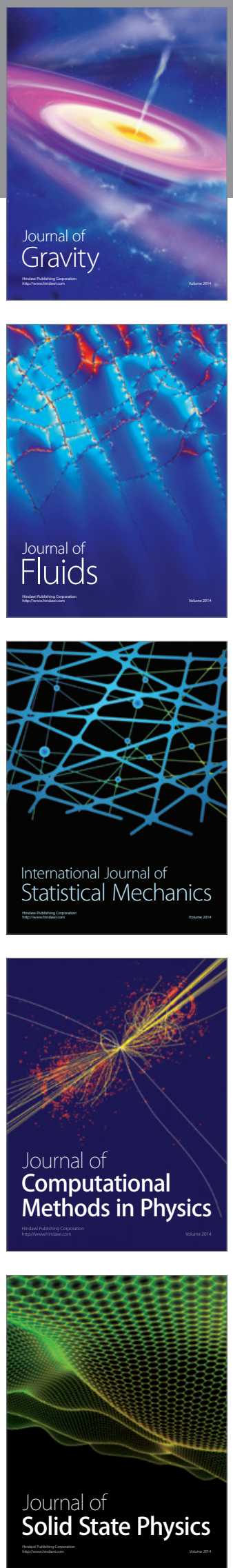

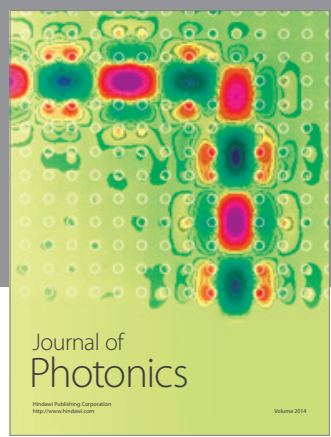

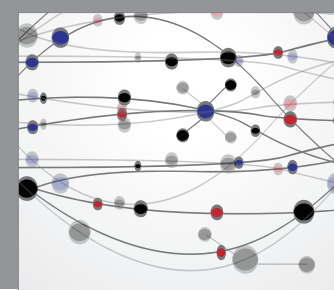

The Scientific World Journal

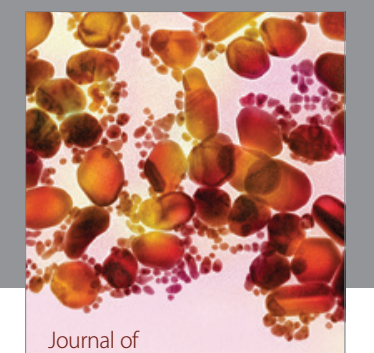

Soft Matter
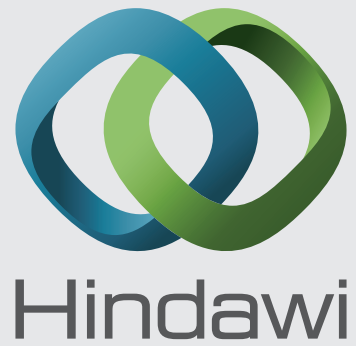

Submit your manuscripts at

http://www.hindawi.com
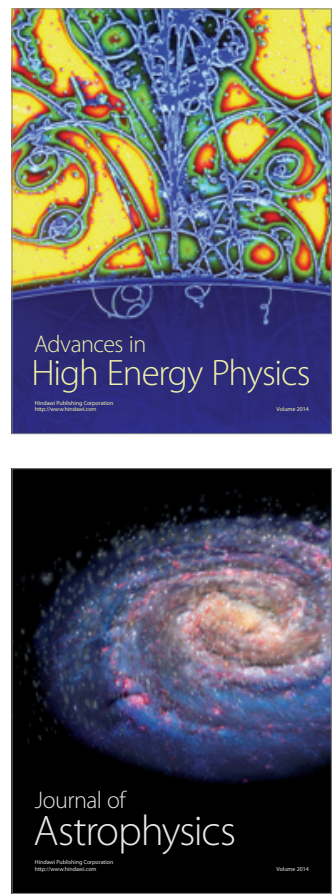
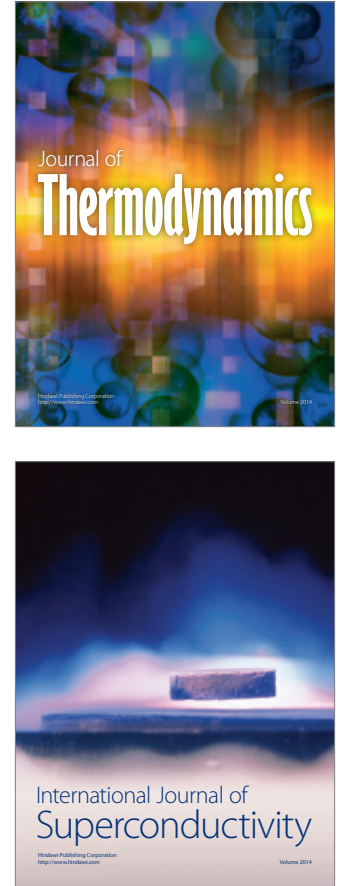
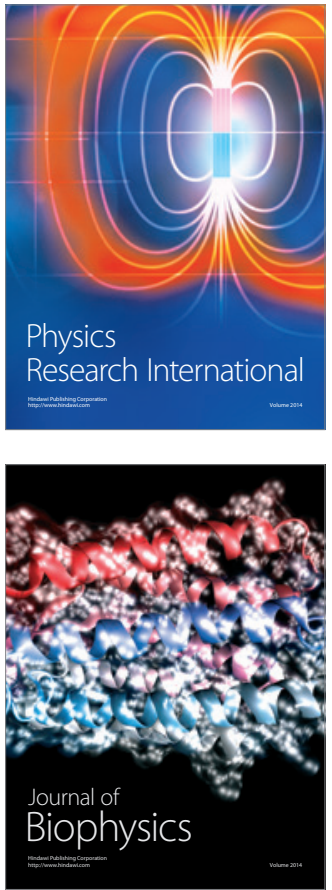
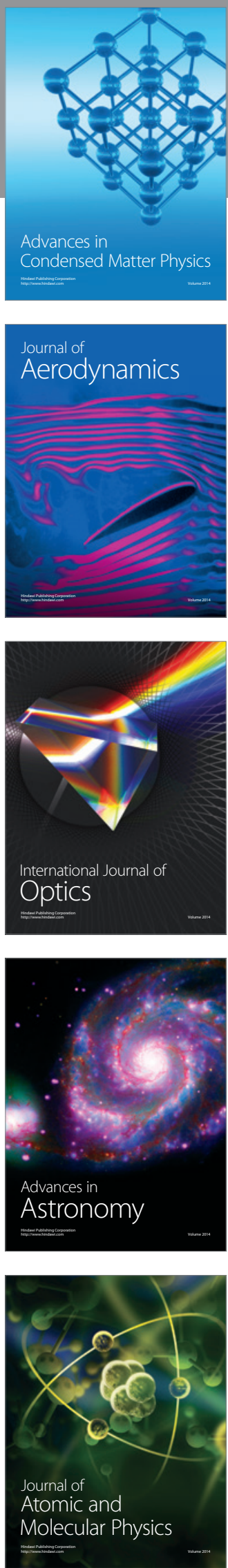